\title{
The outcomes of intra-aortic balloon pump usage in patients with acute myocardial infarction: a comprehensive meta-analysis of 33 clinical trials and 18,889 patients
}

\author{
This article was published in the following Dove Press journal: \\ Patient Preference and Adherence \\ 16 March 2016 \\ Number of times this article has been viewed
}

\author{
Zhong-Guo Fan ${ }^{1, *}$ \\ Xiao-Fei Gao $1,2, *$ \\ Li-Wen Chen' \\ Xiao-Bo $\mathrm{Li}^{1,2}$ \\ Ming-Xue Shao ${ }^{1,2}$ \\ Qian Ji' \\ Hao Zhu' \\ Yi-Zhi Ren' \\ Shao-Liang Chen ${ }^{1,2}$ \\ Nai-Liang Tian ${ }^{1,2}$ \\ 'Department of Cardiology, \\ Nanjing First Hospital, Nanjing \\ Medical University, ${ }^{2}$ Department \\ of Cardiology, Nanjing Heart Center, \\ Nanjing, People's Republic of China \\ *These authors contributed equally \\ to this work
}

Background: The effects of intra-aortic balloon pump (IABP) usage in patients with acute myocardial infarction remain controversial. This study sought to evaluate the outcomes of IABP usage in these patients.

Methods: Medline, EMBASE, and other internet sources were searched for relevant clinical trials. The primary efficacy endpoints (in-hospital, midterm, and long-term mortality) and secondary endpoints (reinfarction, recurrent ischemia, and new heart failure in the hospital) as well as safety endpoints (severe bleeding requiring blood transfusion and stroke in-hospital) were subsequently analyzed.

Results: Thirty-three clinical trials involving 18,889 patients were identified. The risk of longterm mortality in patients suffering from acute myocardial infarction was significantly decreased following IABP use (odds ratio [OR] 0.66, 95\% confidence interval [CI]: 0.48-0.91, $P=0.010$ ). Both in-hospital and midterm mortality did not differ significantly between the IABP use group and no IABP use group (in-hospital: OR 0.87, 95\% CI: 0.59-1.28, $P=0.479$; midterm: OR 1.12, 95\% CI: $0.53-2.38, P=0.768)$. IABP insertion was not associated with the risk reduction of reinfarction, recurrent ischemia, or new heart failure. However, IABP use increased the risk of severe bleeding requiring blood transfusion (OR 2.05, 95\% CI: $1.29-3.25, P=0.002$ ) and stroke (OR 1.71, 95\% CI: 1.04-2.82, $P=0.035$ ). In the thrombolytic therapy and cardiogenic shock subgroups, reduced mortality rates following IABP use were observed.

Conclusion: IABP insertion is associated with feasible benefits with respect to long-term survival rates in patients suffering from acute myocardial infarction, particularly those suffering from cardiogenic shock and receiving thrombolytic therapy, but at the cost of higher incidence of severe bleeding and stroke.

Keywords: intra-aortic balloon pump, acute myocardial infarction, cardiogenic shock, thrombolytic therapy, meta-analysis

\section{Introduction}

Patients suffering from acute myocardial infarction (AMI) are at an increased risk for high mortality, particularly in the setting of AMI complicated by cardiogenic shock (CS), although both emergency revascularization (ERV) and thrombolysis have been widely used. ${ }^{1}$ The intra-aortic balloon pump (IABP) has been widely used since it was first used clinically in 1968. It improves diastolic coronary blood flow and reduces both afterload and myocardial oxygen demand, ${ }^{2}$ changes thought to have positive effects on myocardial recovery following AMI. . $^{3,4}$
Correspondence: Nai-Liang Tian Department of Cardiology, Nanjing First Hospital, Nanjing Medical University,

Number 68 Changle Road, 210006

Nanjing, People's Republic of China

Tel +862552208048

$\mathrm{Fax}+862552208048$

Email tiannailiang@163.com 
According to the American College of Cardiology and American Heart Association (ACC/AHA 2012) guidelines, IABP was recommended for CS and its insertion was suggested at the completion of coronary angiography and revascularization (IIa). ${ }^{5}$ The European Society of Cardiology guidelines also recommended IABP as a bridge to reperfusion for patients suffering from CS. ${ }^{6}$ In recent years, several large randomized controlled trials $(\mathrm{RCTs})^{7-10}$ and meta-analyses ${ }^{11,12}$ have demonstrated only limited or even no benefits with respect to midterm and long-term all-cause mortality in patients with AMI complicated by CS for whom early revascularization was planned. However, two other meta-analyses ${ }^{13,14}$ have demonstrated that IABP has a positive impact with respect to all-cause mortality in these patients for whom thrombolysis was used as a preferred reperfusion strategy. These conflicting data challenged the recommendations of the current guidelines and these aforementioned meta-analyses did not include all the available relevant clinical trials. Therefore, we sought to conduct an updated, comprehensive meta-analysis involving as many clinical trials as possible to evaluate the evidence pertaining to the performance of IABP performed as an adjunct therapy in patients suffering from an AMI complicated with CS or not.

\section{Methods}

\section{Literature search}

We searched Medline, EMBASE, and the Cochrane Controlled Trials Registry from their dates of inception until May 2015 for clinical trials comparing outcomes following IABP use with outcomes in the absence of IABP use (defined as the Control group) following AMI. To be certain all relevant studies were included, the electronic databases were searched using combinations of several relevant keywords, including intra-aortic balloon pump, counterpulsation, acute myocardial infarction, and clinical trials. All potentially relevant articles and references from published reviews and meta-analyses were subsequently screened for eligibility.

\section{Inclusion and exclusion criteria}

The articles were required to meet the following criteria: 1) adult patients suffering from AMI (age from 18 to 90 years), regardless of CS and 2) clinical trials comparing an IABP group and a control group. The exclusion criteria were as follows: 1) nonhuman or ongoing studies; 2) non-English language studies; 3 ) reviews or meta-analyses; 4) duplicated studies or different studies using the sample; and 5) patients supported by other cardiac assist devices.

\section{Data extraction, synthesis, and quality assessment}

Two investigators (FZG and GXF) independently reviewed all relevant articles to assess their eligibility, using standardized data-abstraction forms. Disagreements were resolved by a third investigator (CLW). We extracted the following data from each included study: the name of the trial or first author, publication year, inclusion and exclusion criteria, baseline demographics, and clinical outcomes at the hospital and/or during follow-up. All included studies were divided into two subgroups based on the design of each study, described as RCTs and observational clinical trials (Obs). To account for the effects of treatment, we also grouped the studies by type of reperfusion, as follows: no reperfusion, ERV alone, including either percutaneous transcoronary angioplasty or coronary artery bypass grafting, thrombolytic therapy alone (TT alone), and ERV plus TT. However, the patients with CS were selected as another subgroup to determine whether they responded to IABP insertion. Moreover, the patients with AMI were divided into two subgroups based on whether they underwent IABP insertion before or after reperfusion to determine the best opportunity for IABP insertion. The quality of all retrieved studies was assessed to ensure minimization of bias, but no formal scoring system was used.

\section{Study endpoints}

The primary efficacy endpoint was the rate of all-cause mortality, which was evaluated across three periods based on the follow-up durations of the included trials, including in-hospital mortality, midterm mortality (defined as mortality between 30 days and 2 months), and long-term mortality (defined as mortality after 6 months), and the secondary efficacy endpoints were new heart failure, reinfarction, and recurrent ischemia during hospitalization. The incidences of stroke and severe bleeding requiring blood transfusion in-hospital were evaluated as safety endpoints. The rates of all-cause mortality and new heart failure could be replaced by cardiac death ${ }^{15}$ and pulmonary edema, ${ }^{16}$ respectively, if the included articles did not have the relevant data. The definitions of the clinical endpoints varied slightly among the included trials, and we evaluated the clinical endpoints using standardized definitions.

\section{Statistical analysis}

All endpoints were treated as dichotomous variables, which were analyzed using odds ratio (OR) with $95 \%$ confidence interval (CI). Statistical heterogeneity among the included studies was measured using the Cochrane's Q test and the 
$I^{2}$ statistic. When the $P$-value of Q test was $<0.10$ and/or the $I^{2}$ was $\geq 50 \%$, significant heterogeneity was considered and a random-effects model was selected. If not, the fixedeffects model and the Mantel-Haenszel method were used. Publication bias was examined via Egger's test $(P<0.1$ for significant asymmetry). ${ }^{17}$ To assess the stability of the overall treatment effects, sensitivity analyses (exclude one study at a time) were performed. All $P$-values were two-tailed, and a $P$-value $<0.05$ was considered statistically significant. This meta-analysis was conducted in accordance with the Preferred Reporting Items for Systematic Reviews and Meta-Analysis statements, ${ }^{18}$ and the data were analyzed using STATA 12.0 (StataCorp LP, College Station, TX, USA).

\section{Results}

\section{Eligible studies and patient characteristics}

After screening 1,841 initial articles using the electronic databases, 33 clinical trials were identified, including 15 RCTs $(2,497 \text { patients })^{7-10,15,19-30}$ and 18 Obs (16,392 patients $)^{16,31-49}$ (Figure 1). The baseline characteristics of the included RCTs and Obs are summarized in Tables 1-4.

\section{Primary efficacy endpoint}

\section{In-hospital mortality}

As shown in the Figure 2A, the overall risk of in-hospital mortality was not reduced significantly following IABP use (OR 0.87, 95\% CI: 0.59-1.28, $P=0.479 ; P<0.001$, $I^{2}=90.6 \%$ ); similar results were observed for both the RCTs and Obs (RCT: OR 0.89, 95\% CI: 0.54-1.49, $P=0.669$; $P=0.298, I^{2}=15.7 \%$; Obs: OR 0.84, 95\% CI: 0.52-1.35, $\left.P=0.467 ; P<0.001, P^{2}=94.4 \%\right)$. The results of the Egger's test indicted that no publication bias was encountered $(P=0.406$, $0.325,0.175$ for Obs, RCT, and overall, respectively).

\section{Midterm mortality}

The comparison between IABP use and no IABP use demonstrated no significant differences with respect to the risk of midterm mortality (OR 1.12, 95\% CI: $0.53-2.38, P=0.768$; $P<0.001, P^{2}=93.4 \%$; Figure $2 \mathrm{~B}$ ), as well as no significant reductions in risk in the RCTs and Obs (RCT: OR 0.84, 95\% CI: 0.43-1.64, $P=0.609 ; P=0.122, I^{2}=45.0 \%$; Obs: OR 1.18, 95\% CI: $0.40-3.47, P=0.760 ; P<0.001, P^{2}=95.5 \%$ ). No publication bias was observed based on the results of

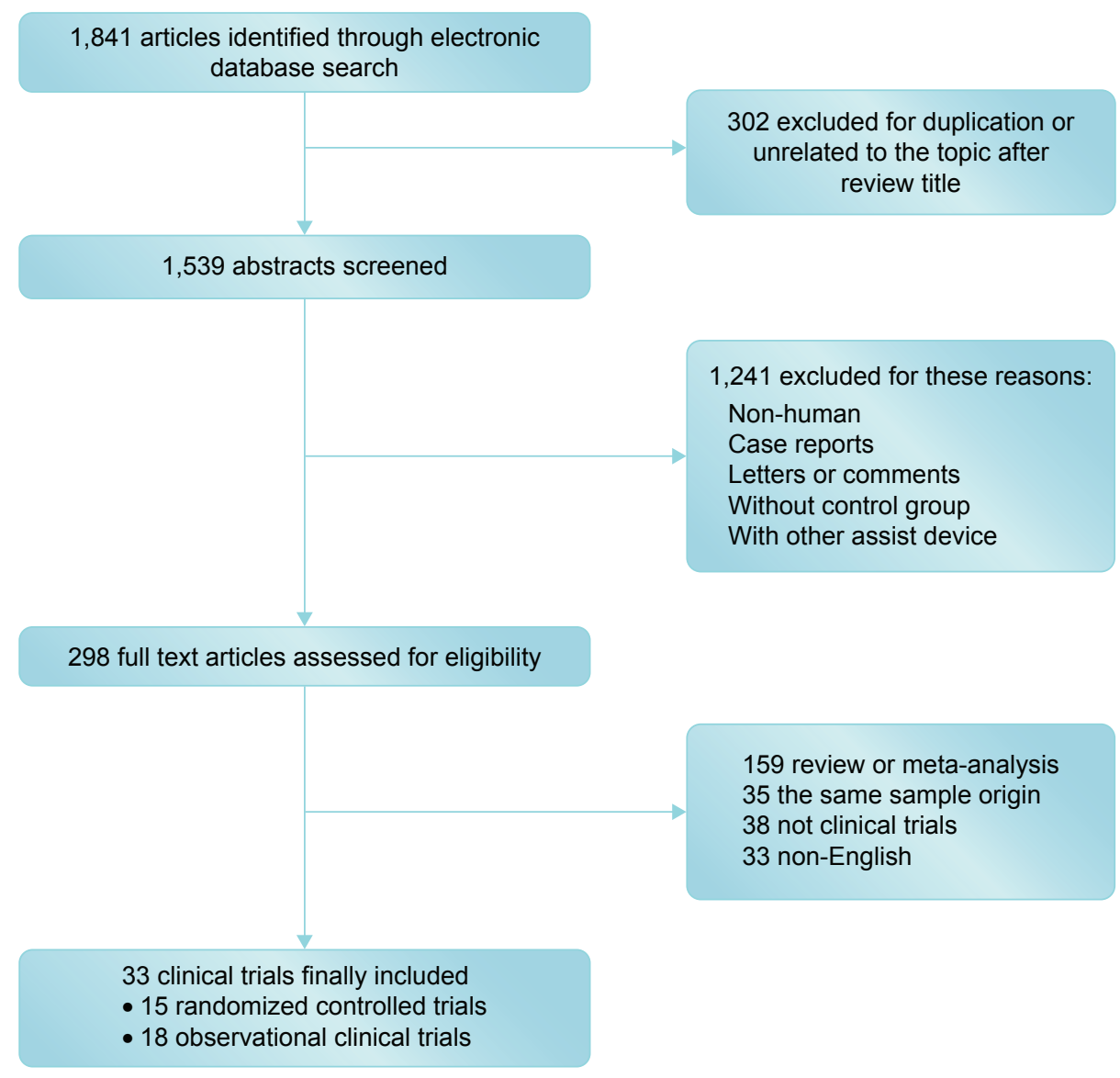

Figure I A flowchart depicting the selection of the studies included in this meta-analysis. 
Table I The characteristics of randomized controlled trials pertaining to the use of an intra-aortic balloon pump in the setting of AMI

\begin{tabular}{|c|c|c|c|c|c|}
\hline Study & Publication year & $\begin{array}{l}\text { Type of reperfusion } \\
\text { for AMI }\end{array}$ & Inclusion criteria & Excluded CS & $\begin{array}{l}\text { Follow-up } \\
\text { duration (d) }\end{array}$ \\
\hline Waksman et a ${ }^{20}$ & 1993 & Thrombolysis & AMI with CS & No & 360 \\
\hline TACTICS 19 & 2005 & Thrombolysis, RV & AMI with hypotension or severe HF & No & 30,180 \\
\hline Li et $\mathrm{al}^{27}$ & 2007 & RV & AMI with CS & No & 360 \\
\hline SHOCK Trial ${ }^{28}$ & 2010 & ERV & AMI with CS & No & In-hospital \\
\hline IABP-SHOCK II7,8 & 2013 & ERV & AMI with CS & No & 30,360 \\
\hline O'Rourke et $\mathrm{al}^{22}$ & 1981 & No reperfusion & AMI with acute HF & NA & 450 \\
\hline Flaherty et al ${ }^{15}$ & 1985 & No reperfusion & AMI without CS & Yes & 14,60 \\
\hline Ohman et $\mathrm{al}^{21}$ & 1994 & ERV & AMI without CS & Yes & In-hospital \\
\hline Kono et $\mathrm{a}^{23}$ & 1996 & Failed thrombolysis & AMI without CS & Yes & 30 \\
\hline PAMI-II $^{24}$ & 1997 & ERV & AMI without CS & Yes & In-hospital \\
\hline Vijayalakshmi et a ${ }^{26}$ & 2007 & ERV & AMI without CS & Yes & 30 \\
\hline Gu et $\mathrm{al}^{29}$ & 2011 & ERV & AMI without CS & Yes & 30,180 \\
\hline CRISP AMI ${ }^{30}$ & 2011 & ERV & AMI without CS & Yes & 30,180 \\
\hline BCIS-I ${ }^{10}$ & 2013 & ERV & AMI without CS & Yes & 1,530 \\
\hline Van't Hof et a ${ }^{25}$ & 1999 & ERV & AMI with $\mathrm{ST} \uparrow / \downarrow>20 \mathrm{~mm}$ & NA & 180 \\
\hline
\end{tabular}

Abbreviations: AMI, acute myocardial infarction; CS, cardiogenic shock; d, days; ERV, emergency revascularization; HF, heart failure; NA, not available; RV, revascularization, including percutaneous transcoronary angioplasty and coronary artery bypass grafting; ST, ST-segments.

the Egger's test $(P=0.135,0.843,0.813$ for Obs, RCT, and overall, respectively).

\section{Long-term mortality}

A significantly lower incidence of long-term mortality rate was observed in the IABP group compared with the control group (OR 0.66, 95\% CI: $0.48-0.91, P=0.010 ; P=0.025$, $I^{2}=47.4 \%$; Figure $2 \mathrm{C}$ ), without publication bias (Egger's test: $P=0.132$ ). A similar result was observed in the RCTs (OR 0.71, 95\% CI: $0.50-0.99, P=0.046 ; P=0.177, P^{2}=30.2 \%$;
Egger's test: $P=0.191$ ), and no significant difference was observed in Obs (OR 0.60, 95\% CI: 0.31-1.19, $P=0.145$; $P=0.012, I^{2}=68.9 \%$; Egger's test: $P=0.359$ ). A sensitivity analysis confirmed the beneficial effects of IABP with respect to the long-term mortality.

\section{Secondary efficacy endpoints}

\section{Reinfarction}

The impact of IABP insertion did not significantly differ from no IABP use with respect to the reduction of risk

Table 2 The characteristics of observational trials pertaining to the use of an intra-aortic balloon pump in the setting of AMI

\begin{tabular}{|c|c|c|c|c|c|}
\hline Study & Publication year & $\begin{array}{l}\text { Type of reperfusion } \\
\text { for AMI }\end{array}$ & Inclusion criteria & Excluded CS & $\begin{array}{l}\text { Follow-up } \\
\text { duration (d) }\end{array}$ \\
\hline Moulopoulos et al ${ }^{3 !}$ & 1986 & No reperfusion & AMI with CS & No & In-hospital \\
\hline Bengtson et $\mathrm{a}^{32}$ & 1992 & NA & AMI with CS & No & In-hospital \\
\hline Stomel et $\mathrm{al}^{133}$ & 1994 & Thrombolysis, ERV & AMI with CS & No & In-hospital \\
\hline Kovack et a ${ }^{35}$ & 1997 & Thrombolysis & AMI with CS & No & 30,360 \\
\hline GUSTO-I ${ }^{34}$ & 1997 & Thrombolysis, RV & AMI with CS & No & 30,360 \\
\hline SHOCK Trial Registry ${ }^{38}$ & 2000 & Thrombolysis, ERV & AMI with suspected CS & No & In-hospital \\
\hline NRMI- $2^{39}$ & 2001 & Thrombolysis, ERV & AMI with CS & No & In-hospital \\
\hline French et $\mathrm{al}^{40}$ & 2003 & Thrombolysis, ERV & AMI with CS & No & 360 \\
\hline Gu et $\mathrm{al}^{41}$ & 2010 & ERV & AMI with CS & No & 30,180 \\
\hline Stub et $\mathrm{al}^{43}$ & 2011 & RV & ACS with CS & No & 30 \\
\hline EHS PCI Registry ${ }^{42}$ & 2011 & ERV & AMI with CS & No & In-hospital \\
\hline $\mathrm{AMC} \mathrm{CS} 49$ & 2012 & ERV & AMI with CS & No & 30 \\
\hline ALKK-PCI Registry ${ }^{45}$ & 2013 & ERV & AMI with CS & No & In-hospital \\
\hline Dziewierz et al ${ }^{46}$ & 2014 & ERV & AMI with CS & No & 30,360 \\
\hline Ohman et $\mathrm{al}^{16}$ & 1991 & Thrombolysis & AMI without CS & Yes & In-hospital \\
\hline Mahmoudi et a ${ }^{44}$ & 2012 & ERV & AMI without CS & Yes & In-hospital \\
\hline Brodie et $\mathrm{al}^{36}$ & 1999 & ERV & AMI without prior TT & NA & 30 \\
\hline Kumbasar et $\mathrm{al}^{37}$ & 1999 & Thrombolysis & $\mathrm{AMI} \leq 6 \mathrm{~h}$ & NA & In-hospital \\
\hline
\end{tabular}

Abbreviations: AMI, acute myocardial infarction; CS, cardiogenic shock; d, days; ERV, emergency revascularization; h, hours; NA, not available; RV, revascularization, including percutaneous transcoronary angioplasty and coronary artery bypass grafting; TT, thrombolytic therapy. 
Table 3 The baseline characteristics of randomized controlled trials pertaining to the use of an IABP in the setting of AMI

\begin{tabular}{|c|c|c|c|c|c|c|}
\hline Study & $\begin{array}{l}\text { Patients, N } \\
\text { (IABP/control) }\end{array}$ & $\begin{array}{l}\text { Mean age, years } \\
\text { (IABP/control) }\end{array}$ & $\begin{array}{l}\text { Male, } \mathrm{n} \\
\text { (IABP/control) }\end{array}$ & $\begin{array}{l}\text { Hypertension, n } \\
\text { (IABP/control) }\end{array}$ & $\begin{array}{l}\text { Diabetes, } n \\
\text { (IABP/control) }\end{array}$ & $\begin{array}{l}\text { Prior MI, } \mathrm{n} \\
\text { (IABP/control) }\end{array}$ \\
\hline Waksman et al ${ }^{20}$ & $24 / 21$ & $66.8 / 67.8$ & $14 / 15$ & $14 / 10$ & NA/NA & $15 / 11$ \\
\hline TACTICS ${ }^{19}$ & $30 / 27$ & $68 * / 67 *$ & $23 / 20$ & NA/NA & $9 / 3$ & $12 / 5$ \\
\hline Li et $\mathrm{al}^{27}$ & $20 / 19$ & $67.4 / 64.9$ & $12 / 12$ & NA/NA & $9 / 8$ & $\mathrm{NA} / \mathrm{NA}$ \\
\hline SHOCK Trial ${ }^{28}$ & $19 / 21$ & $62.1 / 66.1$ & $14 / 17$ & $8 / 10$ & $10 / 10$ & $4 / 5$ \\
\hline IABP-SHOCK II ${ }^{8}$ & $299 / 296$ & $70 * 169 *$ & $202 / 211$ & $213 / 199$ & $105 / 90$ & $71 / 61$ \\
\hline O'Rourke et $\mathrm{a}^{22}$ & $14 / 16$ & $60 / 54$ & $12 / 12$ & NA/NA & $\mathrm{NA} / \mathrm{NA}$ & $2 / 5$ \\
\hline Flaherty et $\mathrm{al}^{15}$ & $10 / 10$ & $52 / 53$ & $9 / 8$ & NA/NA & NA/NA & $4 / 4$ \\
\hline Ohman et $\mathrm{a}^{21}$ & $96 / 86$ & $56 / 55$ & $71 / 65$ & $47 / 37$ & $16 / 15$ & $19 / 20$ \\
\hline Kono et $\mathrm{al}^{23}$ & $23 / 22$ & $54 / 60$ & $20 / 16$ & $10 / 13$ & $6 / 6$ & $\mathrm{NA} / \mathrm{NA}$ \\
\hline PAMI-II ${ }^{24}$ & $211 / 226$ & $64.7 / 63.7$ & $158 / 170$ & $116 / 126$ & $45 / 33$ & $45 / 49$ \\
\hline Vijayalakshmi et al ${ }^{26}$ & $17 / 16$ & $57.5 / 59$ & $14 / 14$ & $6 / 6$ & $3 / 4$ & $2 / 4$ \\
\hline Gu et $\mathrm{a}^{29}$ & $51 / 55$ & $67.4 / 66.6$ & $29 / 36$ & $35 / 33$ & $18 / 19$ & $2 / 3$ \\
\hline CRISP AMI ${ }^{30}$ & $156 / 173$ & $56.1 * / 57.7^{*}$ & $132 / 144$ & $39 / 60$ & $27 / 36$ & $0 / 0$ \\
\hline BCIS- $1^{9,10}$ & $151 / 150$ & $7|/ 7|$ & $122 / 117$ & $95 / 91$ & $56 / 50$ & $113 / 108$ \\
\hline Van't Hof et a $a^{25}$ & $118 / 120$ & $59 / 56$ & $99 / 101$ & NA/NA & $12 / 9$ & $17 / 16$ \\
\hline
\end{tabular}

Note: *Median.

Abbreviations: AMI, acute myocardial infarction; IABP, intra-aortic balloon pump; MI, myocardial infarction; NA, not available.

of reinfarction during hospitalization (OR 1.10, 95\% CI: $0.68-1.78, P=0.706 ; P=0.094, P^{2}=34.3 \%$; Figure $3 \mathrm{~A}$ ), and the results from the RCTs and Obs were similar (Obs: OR 1.25, 95\% CI: $0.48-3.25, P=0.644 ; P=0.027, P=55.6 \%$; RCT: OR $0.91,95 \%$ CI: $0.60-1.40, P=0.680 ; P=0.580, P^{2}=0.0 \%$ ). No publication bias was observed for reinfarction (Egger's test: $P=0.548,0.667,0.837$ for Obs, RCT, and overall, respectively).

\section{Recurrent ischemia}

As depicted in Figure 3B, there was no significant difference between IABP use and no IABP use with respect to the risk of in-hospital ischemia recurrence (OR 0.87, 95\% CI: $\left.0.36-2.12, P=0.754 ; P=0.001, I^{2}=75.7 \%\right)$, in either the RCTs or Obs (RCT: OR 0.49, 95\% CI: $0.18-1.31$, $P=0.155 ; P=0.060, I^{2}=59.4 \%$; Obs: OR $2.31,95 \% \mathrm{CI}$ : $\left.1.20-4.46, P=0.013 ; P=0.744, I^{2}=0.0 \%\right)$. No publication

Table 4 The baseline characteristics of observational clinical trials pertaining to the use of an IABP in the setting of AMI

\begin{tabular}{|c|c|c|c|c|c|c|}
\hline Study & $\begin{array}{l}\text { Patients, N } \\
\text { (IABP/control) }\end{array}$ & $\begin{array}{l}\text { Mean age, years } \\
\text { (IABP/control) }\end{array}$ & $\begin{array}{l}\text { Male, } n \\
\text { (IABP/control) }\end{array}$ & $\begin{array}{l}\text { Hypertension, } \mathbf{n} \\
\text { (IABP/control) }\end{array}$ & $\begin{array}{l}\text { Diabetes, } n \\
\text { (IABP/control) }\end{array}$ & $\begin{array}{l}\text { Prior MI, n } \\
\text { (IABP/control) }\end{array}$ \\
\hline Moulopoulos et $\mathrm{al}^{31}$ & $35 / 14$ & $60.3 / 61.1$ & $29 / 13$ & NA/NA & NA/NA & $6 / 16$ \\
\hline Bengtson et $\mathrm{al}^{32}$ & $99 / 101$ & $64 / 67$ & NA/NA & NA/NA & NA/NA & NA/NA \\
\hline Stomel et $\mathrm{al}^{33}$ & $5 \mathrm{I} / 13$ & $66 / 66$ & $23 / 8$ & $31 / 6$ & $\mathrm{I} \mid / 3$ & $16 / 2$ \\
\hline Kovack et $\mathrm{al}^{35}$ & $27 / 19$ & $62 / 64$ & $16 / 12$ & $10 / 11$ & $7 / 5$ & $6 / 1$ \\
\hline GUSTO-|' & $62 / 248$ & $64 * / 68 *$ & $42 / 154$ & $23 / 99$ & $14 / 57$ & $19 / 67$ \\
\hline Shock Registry ${ }^{38}$ & $439 / 417$ & $65.2 / 73.4$ & $294 / 250$ & $203 / 233$ & $|37 /| 4 \mid$ & $154 / 188$ \\
\hline NRMI- $2^{39}$ & $4,215 / 4,456$ & $\sim 67 / 74.1$ & $\sim 60.5 \% / 50.5 \%$ & $\sim 47 \% / 49 \%$ & $\sim 29 \% / 32 \%$ & $\sim 26 \% / 30 \%$ \\
\hline French et $\mathrm{al}^{40}$ & $260 / 41$ & $65.3 / 67.4$ & $175 / 30$ & $124 / 17$ & $83 / 10$ & $84 / 14$ \\
\hline Gu et $\mathrm{al}^{4 !}$ & $43 / 48$ & $70.4 / 67.9$ & $27 / 31$ & $30 / 32$ & $17 / 17$ & NA/NA \\
\hline Stub et $\mathrm{al}^{43}$ & $251 / 159$ & $65.7 / 67.7$ & $189 / 110$ & $142 / 99$ & $71 / 39$ & $54 / 38$ \\
\hline EHS PCI Registry ${ }^{42}$ & $|62 / 49|$ & $65.3 / 65.4$ & $110 / 335$ & $95 / 316$ & $44 / 138$ & $58 / 136$ \\
\hline $\mathrm{AMC} \mathrm{CS}{ }^{49}$ & $199 / 93$ & $64.7 / 61.5$ & $|36 / 6|$ & $69 / 29$ & $36 / 16$ & $60 / 22$ \\
\hline ALKK-PCI Registry ${ }^{45}$ & $487 / 1,426$ & $67.7 / 69.9$ & $372 / 970$ & $359 / 1,084$ & $159 / 462$ & $17 \mid / 549$ \\
\hline Dziewierz et $\mathrm{al}^{46}$ & $30 / 21$ & $64.5 * / 72 *$ & $25 / 8$ & NA/NA & $8 / 1$ & $8 / 4$ \\
\hline Ohman et $\mathrm{al}^{16}$ & $85 / 725$ & $58 / 56$ & $69 / 580$ & $40 / 297$ & $17 / 102$ & $21 / 87$ \\
\hline Mahmoudi et $\mathrm{al}^{44}$ & $70 / 70$ & $\sim 59 / 60.6$ & $\sim 71.4 \% / 69.2 \%$ & $\sim 73.9 \% / 80 \%$ & $\sim 21.9 \% / 27 \%$ & $\sim 12.4 \% / 9.6 \%$ \\
\hline Brodie et $\mathrm{al}^{36}$ & $213 / 1,277$ & NA/NA & $126 / 916$ & NA/NA & $23 / 85$ & $56 / 229$ \\
\hline Kumbasar et $\mathrm{al}^{37}$ & $25 / 20$ & $53.4 / 53.5$ & $22 / 17$ & $9 / 10$ & $10 / 5$ & NA/NA \\
\hline
\end{tabular}

Note: *Median.

Abbreviations: AMI, acute myocardial infarction; IABP, intra-aortic balloon pump; MI, myocardial infarction; NA, not available. 
A

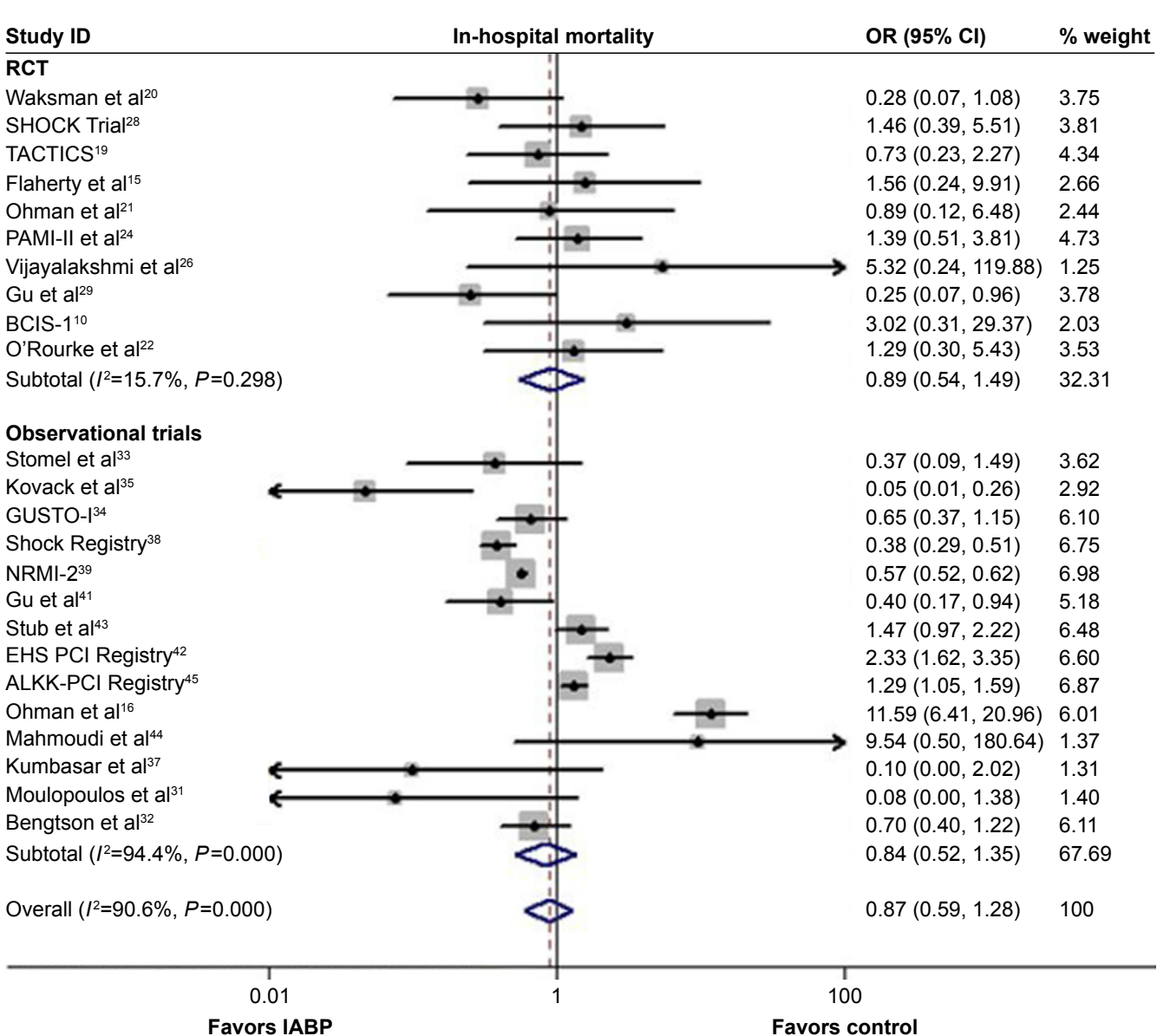

B

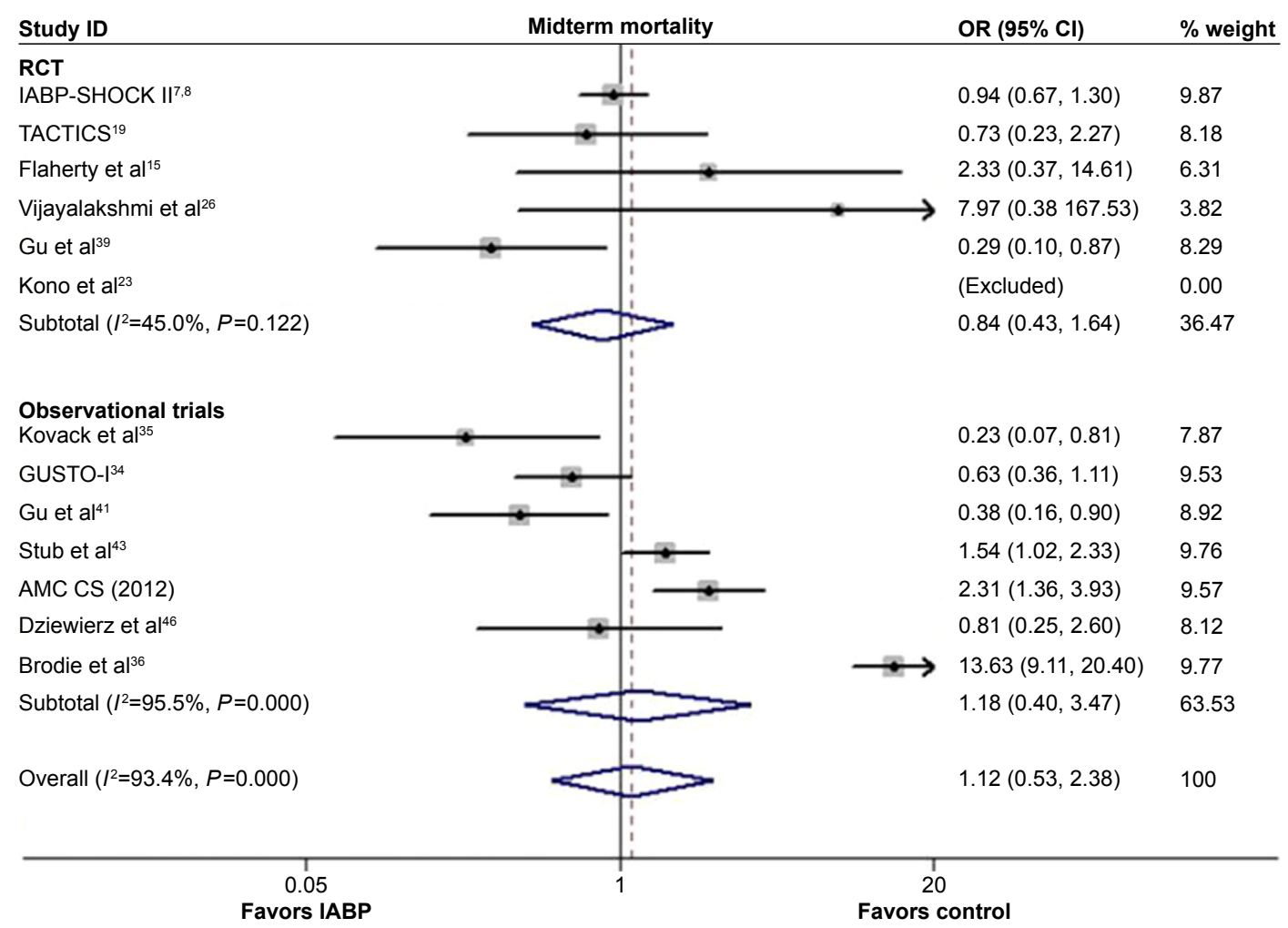

Figure 2 (Continued) 


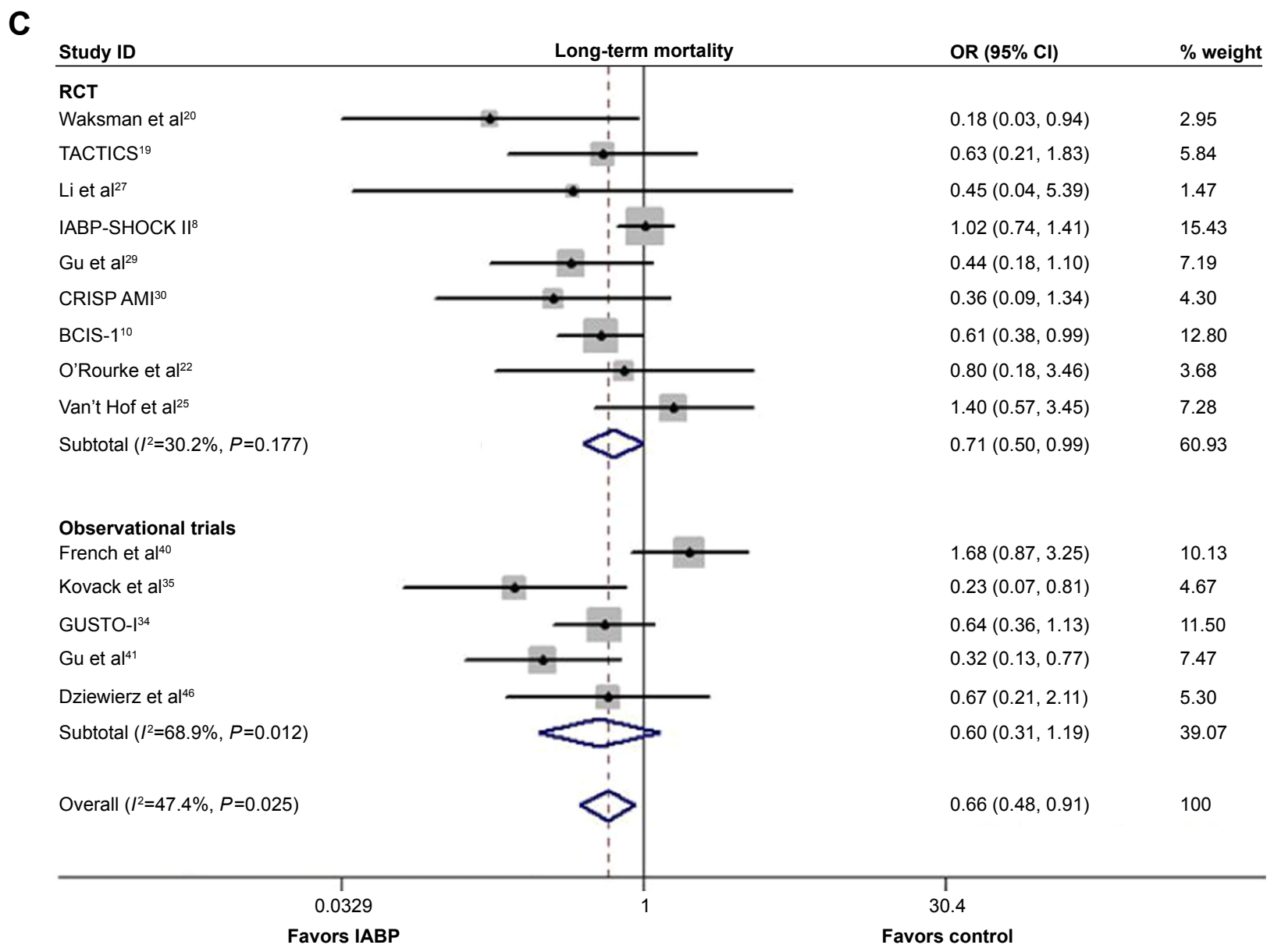

Figure 2 Forest plots of the primary efficacy endpoint of the included trials.

Notes: The odds ratio (OR) of in-hospital all-cause mortality (A), midterm all-cause mortality (B), and long-term all-cause mortality (C), associated with IABP use compared with no IABP use, stratified by different dual regimens. Weights are from random effects analysis.

Abbreviations: $\mathrm{Cl}$, confidence interval; IABP, intra-aortic balloon pump; RCT, randomized controlled trial; ID, identification.

bias was observed $(P=0.855,0.836$ for RCTs and overall, respectively).

\section{New heart failure}

The overall incidence of new heart failure was similar between the two subgroups (OR 1.40, 95\% CI: 0.72-2.72, $P=0.320 ; P<0.001, I^{2}=82.3 \%$; Figure $\left.3 \mathrm{C}\right)$, as well as in the RCTs (OR 0.89, 95\% CI: $0.63-1.28, P=0.541 ; P=0.404$, $I^{2}=2.0 \%$ ), whereas the risk of new heart failure increased significantly in the Obs (OR 3.29, 95\% CI: 1.29-8.38, $P=0.013 ; P=0.005, P=87.5 \%)$. The results from the Egger's test suggested no publication bias regarding the incidence of new heart failure ( $P=0.875,0.866$ for RCTs and overall, respectively).

\section{Safety endpoints}

\section{Severe bleeding requiring blood transfusion}

The incidence of severe bleeding requiring blood transfusion was higher in the IABP group than in control group
(OR 2.05, 95\% CI: $1.29-3.25, P=0.002 ; P=0.001, P^{2}=78.5 \%$; Figure 4A); a similar result was observed in the Obs (OR 3.48, 95\% CI: $\left.2.09-5.79, P<0.001 ; P=0.003, I^{2}=65.1 \%\right)$, whereas no significant difference was observed in RCTs (OR 1.14, 95\% CI: $\left.0.87-1.49, P=0.338 ; P=0.804, I^{2}=0.0 \%\right)$. The Egger's test was not suggestive of publication bias $(P=0.582$, $0.640,0.880$ for Obs, RCTs, and overall, respectively). The sensitivity analysis demonstrated that the inferior effects of IABP insertion in the setting of AMI on severe bleeding requiring blood transfusion were always observed by omitting a single study at a time.

\section{Stroke}

IABP usage was associated with a higher in-hospital incidence of stroke (OR 1.71, 95\% CI: 1.04-2.82, $P=0.035$, Figure 4B) without any heterogeneity $\left(P=0.636, I^{2}=0.0 \%\right)$, which contrasted with the results of RCTs and Obs (OR 1.70, 95\% CI: $0.73-3.97, P=0.220 ; P=0.302, I^{2}=17.3 \%$ for RCTs; Obs: OR 1.72, 95\% CI: 0.93-3.19, $P=0.085$; 
A

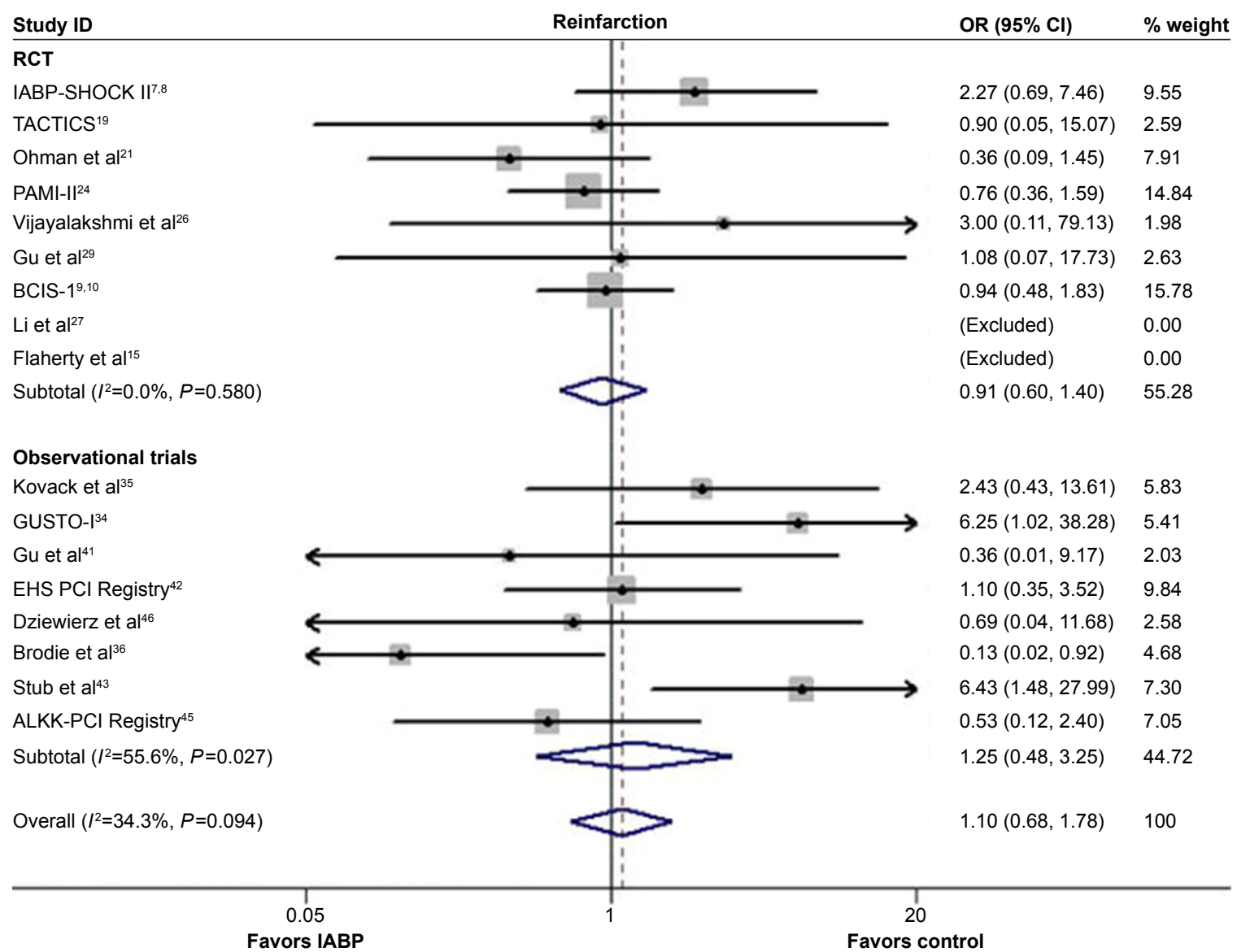

B

Study ID

Recurrent ischemia

OR $(95 \% \mathrm{Cl})$

$\%$ weight

RCT

Flaherty et al ${ }^{15}$

Ohman et $\mathrm{al}^{21}$

Kono et al ${ }^{23}$

PAMI-II ${ }^{24}$

BCIS-I 10

Subtotal $\left(I^{2}=59.4 \%, P=0.060\right)$

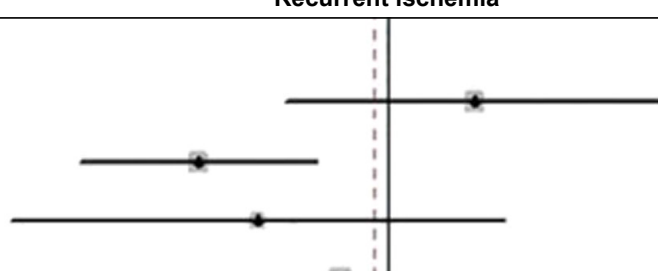

$2.25(0.38,13.47) \quad 12.44$

$0.16(0.05,0.51) \quad 17.83$

$0.29(0.03,3.00) \quad 9.15$

$0.63(0.38,1.06) \quad 23.02$

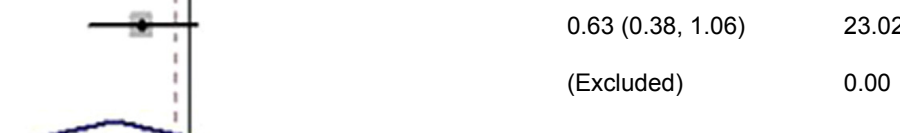

Observational trials

Kovack et al ${ }^{35}$

GUSTO-134

Subtotal $\left(I^{2}=0.0 \%, P=0.744\right)$

Overall $\left(I^{2}=75.7 \%, P=0.001\right)$

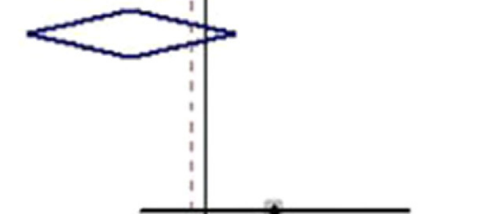

$0.49(0.18,1.31) \quad 62.45$

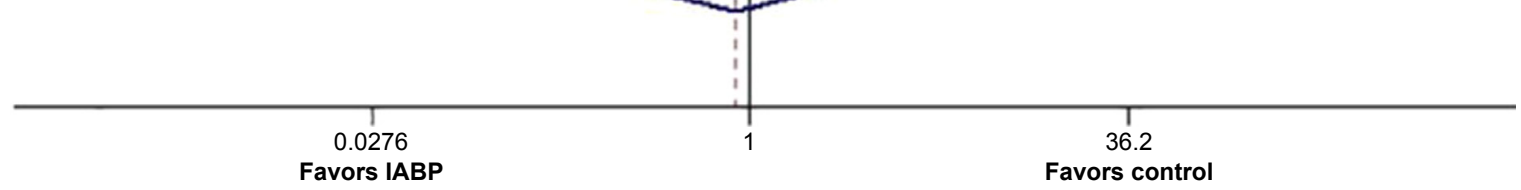

Figure 3 (Continued) 


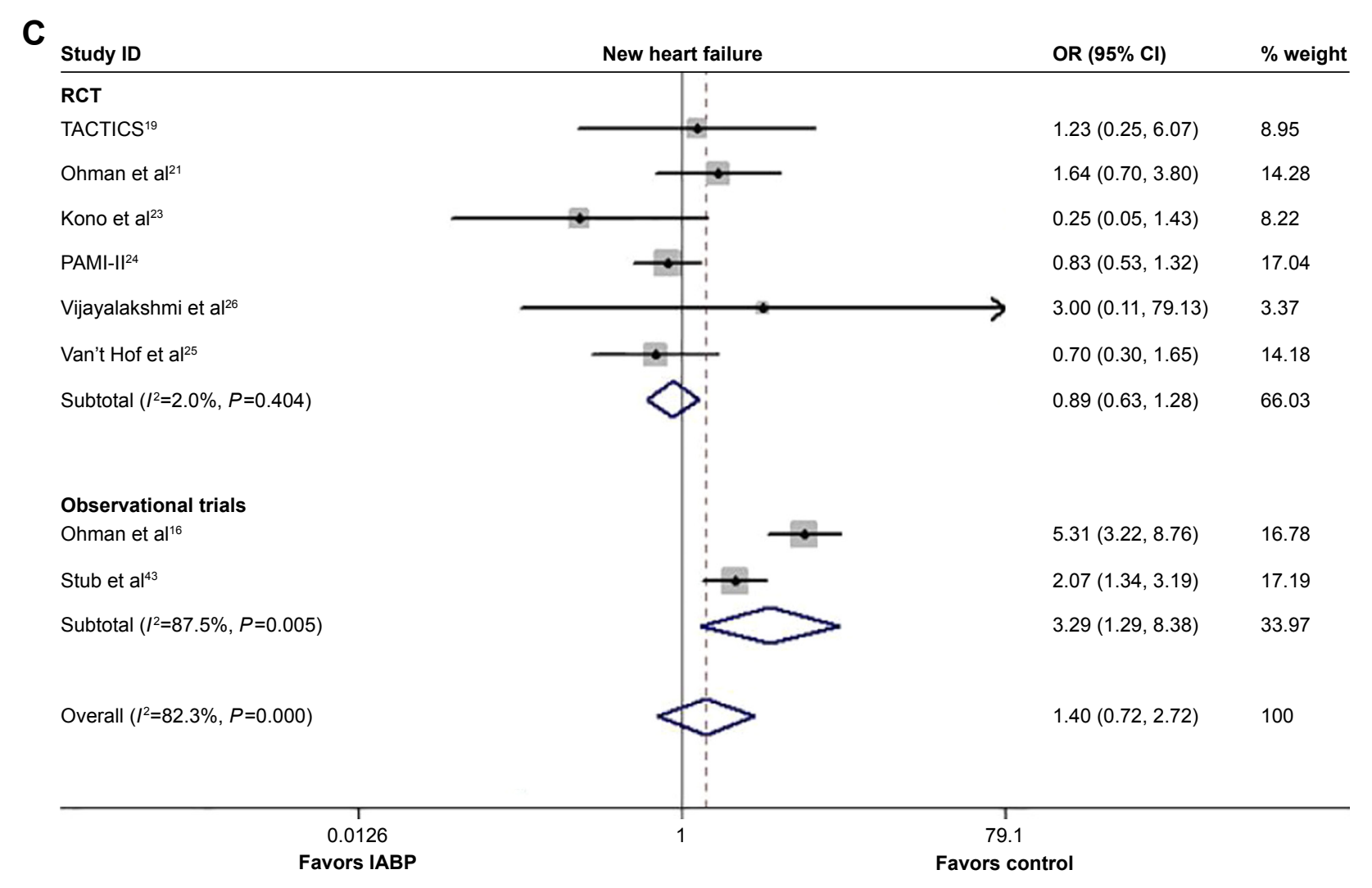

Figure 3 Forest plots of the secondary efficacy endpoint of the included trials.

Notes: The odds ratio $(O R)$ of reinfarction $(\mathbf{A})$, recurrent ischemia $(\mathbf{B})$, and new heart failure $(\mathbf{C})$ associated with IABP use versus no IABP use stratified by different dual regimens. Weights are from random effects analysis.

Abbreviations: $\mathrm{Cl}$, confidence interval; IABP, intra-aortic balloon pump; RCT, randomized controlled trial; ID, identification.

$P=0.704, P^{2}=0.0 \%$ for Obs). No publication bias was noted via Egger's test $(P=0.662,0.142,0.248$ for Obs, RCTs, and overall, respectively).

\section{Subgroup analysis}

In the subgroup of patients suffering from AMI complicated by CS, significantly lower risks of in-hospital and longterm mortality associated with IABP use versus no IABP use were noted (OR 0.68, 95\% CI: 0.46-0.99, $P=0.045$, Figure 5A; OR 0.64, 95\% CI: 0.41-0.996; $P=0.048$, Figure 5B), but no significant difference compared with midterm mortality was observed (OR $0.86,95 \% \mathrm{CI}$ : $0.56-1.35, P=0.521)$.

In the subgroup of reperfusion, the combination of IABP and TT alone resulted in a lower midterm mortality rate (OR 0.42, 95\% CI: $0.23-0.76, P=0.004$, Figure 5C), although no significant differences were observed with respect to in-hospital and long-term mortality (in-hospital: OR 0.55, 95\% CI: $0.21-1.39, P=0.206$; long-term: OR $0.57,95 \% \mathrm{CI}$ : $0.28-1.17, P=0.128$ ). Moreover, the combination of IABP and ERV alone was associated with a lower long-term mortality (OR $0.71,95 \%$ CI: $0.49-1.03, P=0.072$ ).
In the analysis pertaining to the opportunity for IABP insertion, a reduced risk of long-term mortality was observed among the patients suffering AMI for whom IABP was inserted before reperfusion compared with no IABP use (OR $0.49,95 \%$ CI: $0.34-0.71, P<0.001$, Figure 5D), although no significant difference was observed between no IABP use and IABP insertion after reperfusion (OR 0.90, 95\% CI: $0.35-2.31, P=0.825)$.

\section{Discussion}

The major finding of this comprehensive meta-analysis was that IABP insertion was associated with reduced long-term mortality in patients suffering from AMI compared with no IABP use at the cost of potential high risk of stroke and severe bleeding requiring blood transfusion. The subgroup analyses demonstrated that IABP insertion before reperfusion may be an optimal treatment for patients suffering from AMI complicated by CS or patients receiving TT.

Since IABP was first reported for clinical application in $1968,{ }^{4}$ it has been widely used in patients suffering from AMI, particularly patients following AMI complicated by CS. ${ }^{2,50}$ Both the ACC/AHA (2012) ${ }^{5}$ and the European 


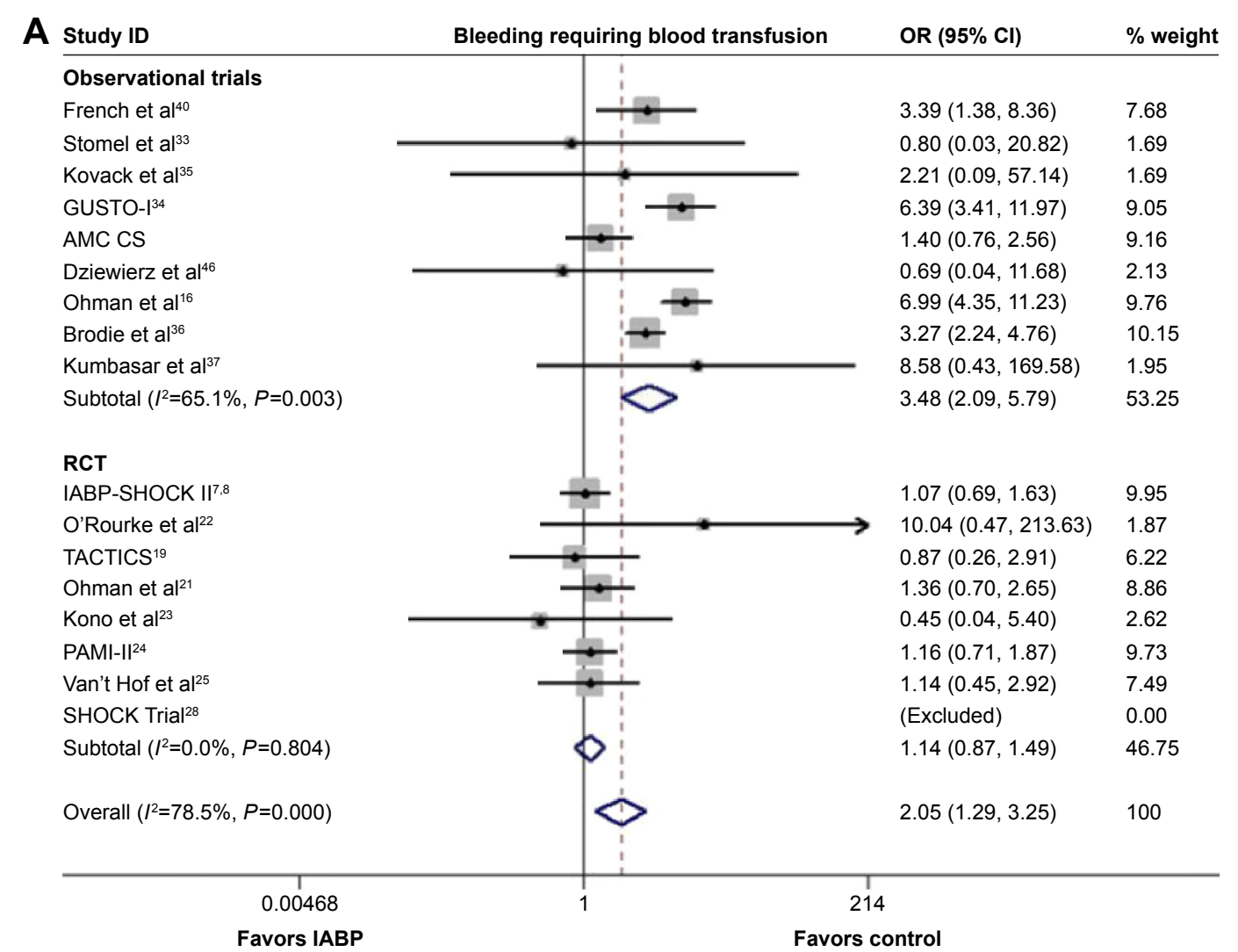

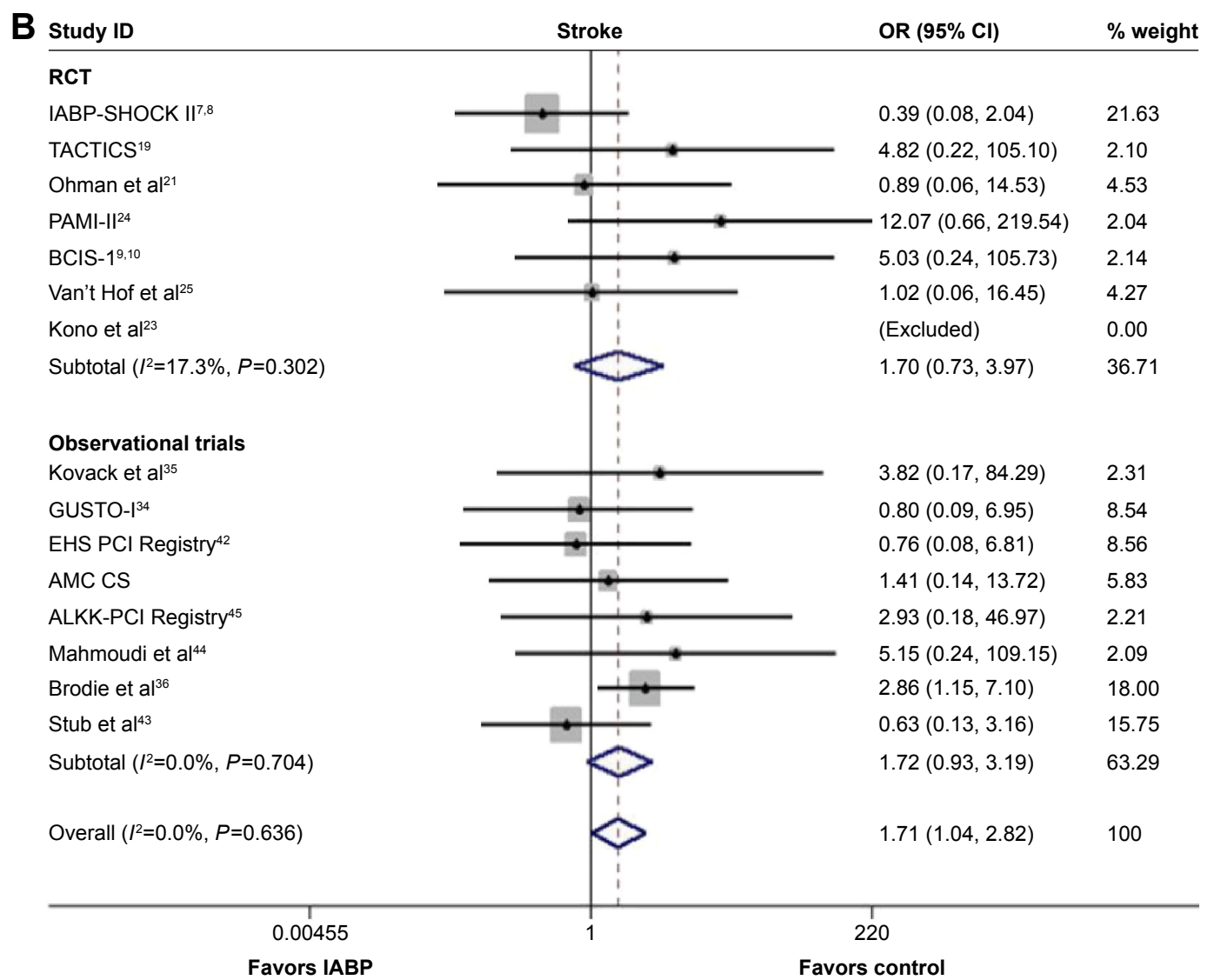

Figure 4 Forest plots of the safety endpoints of the included trials.

Notes: The odds ratio $(O R)$ of severe bleeding requiring blood transfusion $(\mathbf{A})$ and stroke $(\mathbf{B})$ associated with IABP use versus no IABP use stratified by different dual regimens. Weights are from random effects analysis.

Abbreviations: $\mathrm{Cl}$, confidence interval; IABP, intra-aortic balloon pump; RCT, randomized controlled trial; ID, identification. 
Society of Cardiology guidelines ${ }^{6}$ strongly recommended IABP as a bridge to reperfusion for patients suffering from AMI complicated by CS, recommendations derived from several observational clinical trials. ${ }^{31,34,39}$ However, these recommendations have been challenged because of several recent meta-analyses ${ }^{12}$ and RCTs, ${ }^{7-10,19}$ which demonstrated that IABP for patients with AMI complicated by CS was not associated with reduced mortality, but with high potential risks of major bleeding and stroke. The IABP-SHOCK II trial, a randomized, open-label, multicenter trial involving 600 patients with CS following AMI who underwent early revascularization, demonstrated that IABP did not increase either 6- or 12-month survival rates compared with no IABP use. ${ }^{78}$ Moreover, the IABP SHOCK trial ${ }^{28}$ demonstrated that

\begin{tabular}{|c|c|c|c|c|}
\hline & Study ID & In-hospital mortality & OR $(95 \% \mathrm{Cl})$ & $\%$ weight \\
\hline & Moulopoulos et $\mathrm{al}^{31}$ & - & $0.08(0.00,1.38)$ & 1.49 \\
\hline & Bengtson et al ${ }^{32}$ & - & $0.70(0.40,1.22)$ & 8.83 \\
\hline & Waksman et a $\left.\right|^{20}$ & $\rightarrow$ & $0.28(0.07,1.08)$ & 4.61 \\
\hline & SHOCK Trial ${ }^{28}$ & $\rightarrow$ & $1.46(0.39,5.51)$ & 4.70 \\
\hline & Stomel et $a^{33}$ & - & $0.37(0.09,1.49)$ & 4.41 \\
\hline & Kovack et al ${ }^{35}$ & & $0.05(0.01,0.26)$ & 3.41 \\
\hline & GUSTO-I ${ }^{34}$ & + & $0.65(0.37,1.15)$ & 8.83 \\
\hline & Shock Registry ${ }^{38}$ & & $0.38(0.29,0.51)$ & 10.26 \\
\hline & NRMI-2 ${ }^{39}$ & & $0.57(0.52,0.62)$ & 10.82 \\
\hline & TACTICS $^{19}$ & & $0.73(0.23,2.27)$ & 5.54 \\
\hline & Gu et $\mathrm{al}^{29}$ & & $0.40(0.17,0.94)$ & 7.00 \\
\hline & Stub et $\mathrm{al}^{43}$ & + & $1.47(0.97,2.22)$ & 9.65 \\
\hline & EHS PCI Registry ${ }^{42}$ & $\longrightarrow$ & $2.33(1.62,3.35)$ & 9.91 \\
\hline & ALKK-PCI Registry ${ }^{45}$ & $\neq$ & $1.29(1.05,1.59)$ & 10.53 \\
\hline & Overall $\left(I^{2}=90.9 \%, P=0.000\right)$ & & $0.68(0.46,0.99)$ & 100 \\
\hline & 0.02 & $\begin{array}{l}7 \\
1\end{array}$ & $\begin{array}{c}1 \\
50\end{array}$ & \\
\hline & Favors IABP & & Favors control & \\
\hline & Study ID & Long-term mortality & OR $(95 \% \mathrm{Cl})$ & $\%$ weight \\
\hline & Waksman et $\mathrm{al}^{20}$ & & $0.18(0.03,0.94)$ & 5.37 \\
\hline & French et al ${ }^{40}$ & $\rightarrow$ & $1.68(0.87,3.25)$ & 15.30 \\
\hline & TACTICS ${ }^{19}$ & & $0.63(0.21,1.83)$ & 9.82 \\
\hline & Li et $a^{27}$ & & $0.45(0.04,5.39)$ & 2.79 \\
\hline & IABP-SHOCK II ${ }^{8}$ & & $1.02(0.74,1.41)$ & 20.70 \\
\hline & Kovack et al ${ }^{35}$ & & $0.23(0.07,0.81)$ & 8.10 \\
\hline & GUSTO-I ${ }^{34}$ & & $0.64(0.36,1.13)$ & 16.82 \\
\hline & Gu et $a^{\mid 41}$ & & $0.32(0.13,0.77)$ & 12.04 \\
\hline & Dziewierz et al ${ }^{46}$ & & $0.67(0.21,2.11)$ & 9.05 \\
\hline & Overall $\left(I^{2}=58.3 \%, P=0.014\right)$ & & $0.64(0.41,0.996)$ & 100 \\
\hline & $\begin{array}{c}1 \\
0.05\end{array}$ & 1 & $\begin{array}{l}1 \\
20\end{array}$ & \\
\hline & Favors IABP & & Favors control & \\
\hline
\end{tabular}

Figure 5 (Continued) 

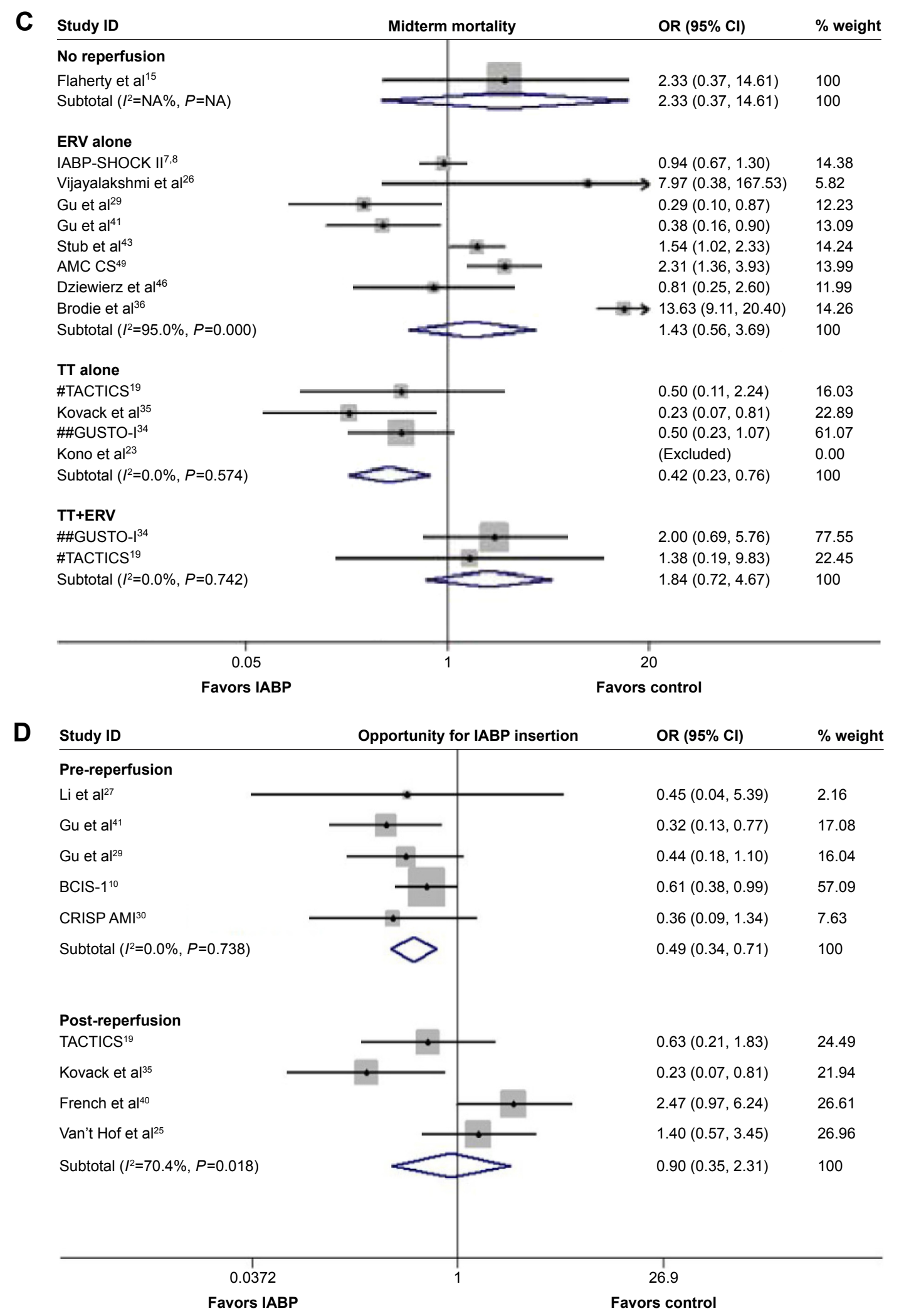

Figure 5 Forest plots of the subgroup analysis of the included trials.

Notes: The odds ratio (OR) of in-hospital all-cause mortality (A) and long-term all-cause mortality (B) among the patients suffering from AMI complicated by CS, as well as midterm all-cause mortality $(\mathbf{C})$ and the long-term mortality associated with different opportunities of IABP insertion vs no IABP use (D) according to reperfusion strategy and IABP insertion associated with IABP use versus no IABP use stratified by different dual regimens. (C) \#: Different groups of patients from the TACTICS trial received the corresponding reperfusion; \#\#: different groups of patients from the GUSTO-I trial received the corresponding reperfusion. Weights are from random effects analysis. Abbreviations: AMI, acute myocardial infarction; Cl, confidence interval; ERV, emergency revascularization; TT, thrombolytic therapy; CS, cardiogenic shock; IABP, intraaortic balloon pump; ID, identification; NA, not available. 
IABP insertion exerted only modest or even no effects on the acute physiology and chronic health evaluation II score as a marker of disease severity, improvements in cardiac index, reduced inflammation, or reduced plasma brain natriuretic peptide levels compared with medical therapy alone. In summary, the current data did not support IABP as a routine treatment for patients with AMI regardless of whether the patients suffered from AMI complicated by CS, which called the above-mentioned guidelines into question. On the other hand, all these over-mentioned meta-analyses for IABP application did not include all available relevant citations and there was none of them grouped meticulously which might cover the beneficial efficacy of IABP on special patients. Therefore, we carried out this updated, comprehensive meta-analysis to explore which patients could benefit mostly from IABP insertion.

In spite of the advances in early revascularization, ${ }^{28}$ the mortality rate of patients suffering from AMI complicated by CS remains high; IABP was empirically preferred with respect to the treatment of these patients. The thrombolysis and counterpulsation to improve survival in myocardial infarction (TACTICS) trial ${ }^{19}$ demonstrated that IABP insertion for patients with AMI complicated by either hypotension or severe heart failure who were receiving thrombolysis was not associated with a significant risk reduction on 6-month mortality, but was associated with increased survival rates for patients in Killip classes III or IV (39\% for combined therapy versus $80 \%$ for fibrinolysis alone). The data from the present study demonstrated the superior effects of IABP in patients suffering from AMI, particularly those complicated with $\mathrm{CS}$, findings consistent with results of two previous metaanalyses. ${ }^{13,14}$ IABP may be the optimal choice for specific patients with AMI, but not for all patients with AMI.

In fact, the observed reductions in mortality secondary to IABP usage may be balanced by the increased rates of stroke and severe bleeding. More and more evidence, including the results from our study, has demonstrated that IABP insertion is associated with a higher incidence of severe bleeding and stroke. Four risk factors for complications following IABP insertion were identified from the Benchmark Registry: ${ }^{51}$ age $\geq 75$ years, female sex, peripheral arterial disease, and body surface area $<1.65 \mathrm{~m}^{2}$. In the meta-analysis published by Sjauw et al, ${ }^{13}$ a significantly increased rate of stroke secondary to IABP use was observed in patients suffering from AMI. Restricting activity due to IABP insertion for long periods may promote the development of venous thrombosis, resulting in an increased risk of all-cause death among affected patients. Moreover, several studies ${ }^{52,53}$ have demonstrated that major bleeding was associated with an increased risk of death, indicating that bleeding was dangerous not only because of the hemorrhaging itself but also because it forced the discontinuation of the IABP and necessary antiplatelet therapy, resulting in higher rates of thrombotic events. Thiele et $\mathrm{al}^{7,8}$ pointed out that the higher in-hospital mortality in the AMI patients complicated with CS might depend on hemodynamic deterioration, multiorgan dysfunction, or systemic inflammatory response syndrome. One more possible related point was that some of the included patients were too serious to receive the implantation of IABP before their deaths or even had no access to implant this equipment in time if they were initially treated in a peripheral center. In contrast, the lower long-term mortality among these patients might be due to the successful insertion of IABP which positively affected myocardial recovery following AMI. Therefore, it may be more useful to determine which patients benefit most from IABP insertion, as opposed to studying the complications of IABP use.

In contrast to the recommendations of the $\mathrm{ACC} / \mathrm{AHA}$ (2012) guidelines, the SHOCK trial ${ }^{28}$ demonstrated that a higher rate of in-hospital mortality was observed among the patients suffering from AMI complicated by CS associated with IABP insertion following reperfusion compared with no IABP use (36.8\% vs $28.6 \%$ ). However, the balloon pump-assisted coronary intervention study (BCIS-1) trial ${ }^{10}$ demonstrated that IABP insertion before reperfusion may result in a significantly reduced risk of long-term mortality among these patients. Therefore, a subgroup analysis was conducted in our study to address this controversy and determine the ideal opportunity for IABP insertion, as well as which patients may benefit most from IABP insertion. IABP usage was associated with a lower risk of mortality when inserted before reperfusion, a finding consistent with those of previous studies. ${ }^{10,27}$ Early IABP insertion promoted hemodynamic stability and reduced myocardial oxygen demand, which may be important in patients suffering from AMI complicated by $\mathrm{CS}^{2}$ Our results indicated that IABP insertion was associated with feasible benefits with respect to long-term survival in patients with AMI, particularly patients suffering from AMI complicated by CS and patients receiving thrombolytic therapy.

Several questions remained unanswered. First, there were not enough data to assess the optimal duration of IABP insertion for patients without severe complications, as well as for which patients the IABP may be removed at an earlier time. Most of current literature regarding the efficacy of IABP use consented to a duration of $\sim 48$ hours, although no 
absolute benefits regarding survival rates were demonstrated. A second dilemma involved the ideal opportunity for IABP insertion in patients with AMI complicated by hemodynamic compromise. The ACC/AHA (2012) guidelines recommend implantation at the completion of reperfusion. ${ }^{5}$ Third, divergence regarding specifics about the reperfusion strategies was observed. Both ERV alone and TT alone demonstrated potential benefits in patients with AMI in this meta-analysis. Therefore, powerful randomized clinical trials comparing IABP use and no IABP use in patients suffering from AMI complicated by CS focusing on the optimal duration of IABP, most suitable time for IABP insertion, and more precise reperfusion strategies must be performed to guide clinical decision making.

\section{Limitations}

This study had several limitations. First, this meta-analysis was not based on individual patient data, and the small sample size of several included RCTs also made the evaluation of IABP's efficacy easily influenced. Second, different studies used different endpoint definitions, which may have been the source of bias. Third, the lack of other potential confounding factors, such as the time of IABP insertion, duration of IABP placement, insertion details, including technology and choice of sheath with different sizes, as well as reperfusion strategies, did not allow us to explore the effects of IABP on patients with AMI or the underlying mechanisms of these effects. Additionally, there was no uniform or clear follow-up period.

\section{Conclusion}

IABP insertion is associated with feasible benefits with respect to long-term survival in patients with AMI, particularly those suffering from CS and receiving thrombolytic therapy, at the cost of higher risk of severe bleeding and stroke.

\section{Acknowledgment}

The study was supported by the Jiangsu Provincial Special Program of Medical Science (BL2013001).

\section{Author contributions}

$\mathrm{Z}-\mathrm{GF}$ and $\mathrm{X}-\mathrm{FG}$ were involved in the design, literature searching, assessment of study quality, and drafted the manuscript. Disagreements were resolved by L-WC. X-BL and M-XS revised critically the manuscript. Z-GF and $\mathrm{X}-\mathrm{FG}$ performed statistical analysis and critically revised the manuscript. QJ, HZ, and Y-ZR constructed the maps. S-LC and N-LT critically revised original study design and the manuscript. All authors contributed toward data analysis, drafting and critically revising the paper and agree to be accountable for all aspects of the work.

\section{Disclosure}

The authors report no conflicts of interest in this work.

\section{References}

1. Goldberg RJ, Spencer FA, Gore JM, Lessard D, Yarzebski J. Thirtyyear trends (1975 to 2005) in the magnitude of, management of, and hospital death rates associated with cardiogenic shock in patients with acute myocardial infarction: a population-based perspective. Circulation. 2009;119(9):1211-1219.

2. Scheidt S, Wilner G, Mueller H, et al. Intra-aortic balloon counterpulsation in cardiogenic shock. Report of a co-operative clinical trial. N Engl J Med. 1973;288(19):979-984.

3. Kern MJ, Aguirre F, Bach R, Donohue T, Siegel R, Segal J. Augmentation of coronary blood flow by intra-aortic balloon pumping in patients after coronary angioplasty. Circulation. 1993;87(2):500-511.

4. Kantrowitz A, Tjonneland S, Freed PS, Phillips SJ, Butner AN, Sherman JL Jr. Initial clinical experience with intraaortic balloon pumping in cardiogenic shock. JAMA. 1968;203(2):113-118.

5. Anderson JL, Adams CD, Antman EM, et al. 2012 ACCF/AHA focused update incorporated into the ACCF/AHA 2007 guidelines for the management of patients with unstable angina/non-ST-elevation myocardial infarction. J Am Coll Cardiol. 2013;61(23):e179-e347.

6. Kolh P, Wijns W, Danchin N, et al. Guidelines on myocardial revascularization. Eur J Cardiothoracic Surg. 2010;38:S1-S52.

7. Thiele H, Zeymer U, Neumann FJ, et al. Intraaortic balloon support for myocardial infarction with cardiogenic shock. NEngl J Med. 2012; 367(14): 1287.

8. Thiele H, Zeymer U, Neumann FJ, et al. Intra-aortic balloon counterpulsation in acute myocardial infarction complicated by cardiogenic shock (IABP-SHOCK II): final 12 month results of a randomised, open-label trial. Lancet. 2013;382(9905):1638-1645.

9. Perera D, Stables R, Thomas M, et al. Elective intra-aortic balloon counterpulsation during high-risk percutaneous coronary intervention: a randomized controlled trial. JAMA. 2010;304(8):867-874.

10. Perera D, Stables R, Clayton T, et al. Long-term mortality data from the balloon pump-assisted coronary intervention study (BCIS-1): a randomized, controlled trial of elective balloon counterpulsation during high-risk percutaneous coronary intervention. Circulation. 2013;127(2):207-212.

11. Su D, Yan B, Guo L, et al. Intra-aortic balloon pump may grant no benefit to improve the mortality of patients with acute myocardial infarction in short and long term. J Pediatr Gastroenterol Nutr. 2015; 94(19):1-7.

12. Ahmad Y, Sen S, Shun-Shin MJ, et al. Intra-aortic balloon pump therapy for acute myocardial infarction. JAMA Intern Med. 2015;175(6):931.

13. Sjauw KD, Engstrom AE, Vis MM, et al. A systematic review and meta-analysis of intra-aortic balloon pump therapy in ST-elevation myocardial infarction: should we change the guidelines? Eur Heart J. 2008;30(4):459-468.

14. Romeo F, Acconcia MC, Sergi D, et al. The outcome of intra-aortic balloon pump support in acute myocardial infarction complicated by cardiogenic shock according to the type of revascularization: A comprehensive meta-analysis. Am Heart J. 2013;165(5):679-692.

15. Flaherty JT, Becker LC, Weiss JL, et al. Results of a randomized prospective trial of intraaortic balloon counterpulsation and intravenous nitroglycerin in patients with acute myocardial infarction. $J$ Am Coll Cardiol. 1985;6(2):434-446.

16. Ohman EM, Califf RM, George BS, et al. The use of intraaortic balloon pumping as an adjunct to reperfusion therapy in acute myocardial infarction. The Thrombolysis and Angioplasty in Myocardial Infarction (TAMI) Study Group. Am Heart J. 1991;121(3 Pt 1):895-901. 
17. Egger M, Davey SG, Schneider M, Minder C. Bias in meta-analysis detected by a simple, graphical test. BMJ. 1997;315(7109):629-634.

18. Liberati A, Altman DG, Tetzlaff J, et al. The PRISMA statement for reporting systematic reviews and meta-analyses of studies that evaluate healthcare interventions: explanation and elaboration. BMJ. 2009; 339:b2700.

19. Ohman EM, Nanas J, Stomel RJ, et al. Thrombolysis and counterpulsation to improve survival in myocardial infarction complicated by hypotension and suspected cardiogenic shock or heart failure: results of the TACTICS Trial. J Thromb Thrombolysis. 2005;19(1):33-39.

20. Waksman R, Weiss AT, Gotsman MS, Hasin Y. Intra-aortic balloon counterpulsation improves survival in cardiogenic shock complicating acute myocardial infarction. Eur Heart J. 1993;14(1):71-74.

21. Ohman EM, George BS, White CJ, et al. Use of aortic counterpulsation to improve sustained coronary artery patency during acute myocardial infarction. Results of a randomized trial. The Randomized IABP Study Group. Circulation. 1994;90(2):792-799.

22. O’Rourke MF, Norris RM, Campbell TJ, Chang VP, Sammel NL. Randomized controlled trial of intraaortic balloon counterpulsation in early myocardial infarction with acute heart failure. Am J Cardiol. 1981; 47(4):815-820.

23. Kono $\mathrm{T}$, Morita $\mathrm{H}$, Nishina $\mathrm{T}$, et al. Aortic counterpulsation may improve late patency of the occluded coronary artery in patients with early failure of thrombolytic therapy. J Am Coll Cardiol. 1996;28(4):876-881.

24. Stone GW, Marsalese D, Brodie BR, et al. A prospective, randomized evaluation of prophylactic intraaortic balloon counterpulsation in high risk patients with acute myocardial infarction treated with primary angioplasty. Second Primary Angioplasty in Myocardial Infarction (PAMI-II) Trial Investigators. J Am Coll Cardiol. 1997;29(7):1459-1467.

25. Van't Hof AW, Liem AL, de Boer MJ, Hoorntje JC, Suryapranata H, Zijlstra F. A randomized comparison of intra-aortic balloon pumping after primary coronary angioplasty in high risk patients with acute myocardial infarction. Eur Heart J. 1999;20(9):659-665.

26. Vijayalakshmi K, Kunadian B, Whittaker VJ, et al. Intra-aortic counterpulsation does not improve coronary flow early after PCI in a high-risk group of patients: observations from a randomized trial to explore its mode of action. J Invasive Cardiol. 2007;19(8):339-346.

27. Li JL, Xue H, Wang BS, et al. Effect of prolonged intra-aortic balloon pumping in patients with cardiogenic shock following acute myocardial infarction. Med Sci Monit. 2007;13(6):R270-R274.

28. Prondzinsky R, Lemm H, Swyter M, et al. Intra-aortic balloon counterpulsation in patients with acute myocardial infarction complicated by cardiogenic shock: The prospective, randomized IABP SHOCK Trial for attenuation of multiorgan dysfunction syndrome. Critical Care Med 2010;38(1):152-160.

29. Gu J, Hu W, Xiao H, et al. Prophylactic intra-aortic balloon pump reduces C-reactive protein levels and early mortality in high-risk patients undergoing percutaneous coronary intervention. Acta Cardiol. 2011;66(4):499-504.

30. Patel MR, Smalling RW, Thiele H, et al. Intra-aortic balloon counterpulsation and infarct size in patients with acute anterior myocardial infarction without shock: the CRISP AMI randomized trial. JAMA. 2011;306(12):1329-1337.

31. Moulopoulos S, Stamatelopoulos S, Petrou P. Intraaortic balloon assistance in intractable cardiogenic shock. Eur Heart J. 1986;7(5): 396-403.

32. Bengtson JR, Kaplan AJ, Pieper KS, et al. Prognosis in cardiogenic shock after acute myocardial infarction in the interventional era. $J \mathrm{Am}$ Coll Cardiol. 1992;20(7):1482-1489.

33. Stomel RJ, Rasak M, Bates ER. Treatment strategies for acute myocardial infarction complicated by cardiogenic shock in a community hospital. Chest. 1994;105(4):997-1002.

34. Anderson RD, Ohman EM, Holmes DJ, et al. Use of intraaortic balloon counterpulsation in patients presenting with cardiogenic shock: observations from the GUSTO-I Study. Global Utilization of Streptokinase and TPA for Occluded Coronary Arteries. J Am Coll Cardiol. 1997;30(3):708-715.
35. Kovack PJ, Rasak MA, Bates ER, Ohman EM, Stomel RJ. Thrombolysis plus aortic counterpulsation: improved survival in patients who present to community hospitals with cardiogenic shock. J Am Coll Cardiol. 1997; 29(7):1454-1458.

36. Brodie BR, Stuckey TD, Hansen C, Muncy D. Intra-aortic balloon counterpulsation before primary percutaneous transluminal coronary angioplasty reduces catheterization laboratory events in high-risk patients with acute myocardial infarction. Am J Cardiol. 1999;84(1):18-23.

37. Kumbasar SD, Semiz E, Sancaktar O, Yalçinkaya S, Ermiş C, Değer N. Concomitant use of intraaortic balloon counterpulsation and streptokinase in acute anterior myocardial infarction. Angiology. 1999;50(6):465-471.

38. Sanborn TA, Sleeper LA, Bates ER, et al. Impact of thrombolysis, intra-aortic balloon pump counterpulsation, and their combination in cardiogenic shock complicating acute myocardial infarction: a report from the SHOCK Trial Registry. Should we emergently revascularize occluded coronaries for cardiogenic shock? J Am Coll Cardiol. 2000; 36(3 Suppl A):1123-1129.

39. Barron HV, Every NR, Parsons LS, et al. The use of intra-aortic balloon counterpulsation in patients with cardiogenic shock complicating acute myocardial infarction: Data from the National Registry of Myocardial Infarction 2. Am Heart J. 2001;141(6):933-939.

40. French JK, Feldman HA, Assmann SF, et al. Influence of thrombolytic therapy, with or without intra-aortic balloon counterpulsation, on 12-month survival in the SHOCK trial. Am Heart J. 2003;146(5): 804-810.

41. Gu J, Hu W, Xiao H, Feng X, Chen Y, Zhang D. Intra-aortic balloon pump improves clinical prognosis and attenuates C-reactive protein level in acute STEMI complicated by cardiogenic shock. Cardiology. 2010;117(1):75-80

42. Zeymer U, Bauer T, Hamm C, et al. Use and impact of intra-aortic balloon pump on mortality in patients with acute myocardial infarction complicated by cardiogenic shock: results of the Euro Heart Survey on PCI. EuroIntervention. 2011;7(4):437-441.

43. Stub D, Chan W, Clark D. Are intra-aortic balloon pumps harmful in cardiogenic shock? Heart Lung Circ. 2011;20:S115.

44. Mahmoudi M, Hauville C, Gaglia MA, et al. The impact of intra-aortic balloon counter-pulsation on in-hospital mortality in patients presenting with anterior ST-elevation myocardial infarction without cardiogenic shock. Cardiovasc Revasc Med. 2012;13(6):328-330.

45. Zeymer U, Hochadel M, Hauptmann K, et al. Intra-aortic balloon pump in patients with acute myocardial infarction complicated by cardiogenic shock: results of the ALKK-PCI registry. Clin Res Cardiol. 2013;102(3):223-227.

46. Dziewierz A, Siudak Z, Rakowski T, Kleczyński P, Zasada W, Dudek D. Impact of intra-aortic balloon pump on long-term mortality of unselected patients with ST-segment elevation myocardial infarction complicated by cardiogenic shock. Postepy Kardiol Interwencyjnej. 2014;10(3):175-180.

47. Vis MM, Sjauw KD, van der Schaaf RJ, et al. Prognostic value of admission hemoglobin levels in ST-segment elevation myocardial infarction patients presenting with cardiogenic shock. Am J Cardiol. 2007;99(9):1201-1202.

48. Vis MM, Sjauw KD, van der Schaaf RJ, et al. In patients with STsegment elevation myocardial infarction with cardiogenic shock treated with percutaneous coronary intervention, admission glucose level is a strong independent predictor for 1-year mortality in patients without a prior diagnosis of diabetes. Am Heart J. 2007;154(6): 1184-1190.

49. Sjauw KD, Engström AE, Vis MM, et al. Efficacy and timing of intra-aortic counterpulsation in patients with ST-elevation myocardial infarction complicated by cardiogenic shock. Neth Heart J. 2012; 20(10):402-409.

50. Thiele H, Allam B, Chatellier G, Schuler G, Lafont A. Shock in acute myocardial infarction: the Cape Horn for trials? Eur Heart $J$. 2010;31(15):1828-1835. 
51. Kimura Y, Ohba K, Sumida H, et al. A survival case of cardiogenic shock due to left main coronary artery myocardial infarction: successful cooperation with on-site percutaneous coronary intervention and helicopter emergency medical service. Intern Med. 2012;51(14):1845-1850.

52. Doyle BJ, Rihal CS, Gastineau DA, Holmes DJ. Bleeding, blood transfusion, and increased mortality after percutaneous coronary intervention: implications for contemporary practice. J Am Coll Cardiol. 2009; 53(22):2019-2027.
53. Chhatriwalla AK, Amin AP, Kennedy KF, et al. Association between bleeding events and in-hospital mortality after percutaneous coronary intervention. JAMA. 2013;309(10):1022-1029.

\section{Publish your work in this journal}

Patient Preference and Adherence is an international, peer-reviewed, open access journal that focuses on the growing importance of patient preference and adherence throughout the therapeutic continuum. Patient satisfaction, acceptability, quality of life, compliance, persistence and their role in developing new therapeutic modalities and compounds to optimize clinical outcomes for existing disease states are major areas of interest for the journal. This journal has been accepted for indexing on PubMed Central. The manuscript management system is completely online and includes a very quick and fair peer-review system, which is all easy to use. Visit http://www dovepress.com/testimonials.php to read real quotes from published authors.

Submit your manuscript here: http://www.dovepress.com/patient-preference-and-adherence-journal 